\title{
Ocean meets river: connecting Bureau of Meteorology ocean forecasts and river height predictions for improved flood warnings
}

\author{
$\underline{\text { Andy Taylor }}^{\text {a }}$, Adam Smith ${ }^{\mathrm{b}}$, Wei Wang ${ }^{\mathrm{c}}$, Justin Robinson ${ }^{\mathrm{c}}$ and Gary Brassington ${ }^{\mathrm{a}}$ \\ ${ }^{\mathrm{a} C e n t r e}$ for Australian Weather and Climate Research, Bureau of Meteorology, Melbourne. \\ ${ }^{\mathrm{b}}$ Climate and Water Division, Bureau of Meteorology, Melbourne. \\ ${ }^{\mathrm{c} C}$ limate and Water Division, Bureau of Meteorology, Sydney. \\ Email: a.taylor@bom.gov.au
}

\begin{abstract}
The Bureau of Meteorology maintains several operational forecasting systems; these include routine global models to forecast weather, climate, and now ocean circulation (OceanMAPS). The Bureau is also the lead federal agency responsible for the provision of a flood warning service within Australia. Some important locations used for flood forecasting and warning are near enough to the ocean that river height forecasts cannot disregard variations in nearby coastal sea level. At such locations the Bureau's operational event-based flood forecasting system employs official harmonic tide predictions together with a dependant rating curve to account for this effect.
\end{abstract}

The relatively recent availability of routine operational OceanMAPS non-tidal sea level forecasts for the Australian region has lead to the development of a modified sea level forecast that includes both tidal and non-tidal effects. The non-tidal effects represented by OceanMAPS include both local effects (e.g., surge, boundary current and eddy impingement) and non-local effects (e.g., coastal trapped waves). This paper demonstrates incorporation of routine sea level forecasts into coastal river height predictions at three sites within the flood forecasting system. The quantified results are in the form of a simple case study based on recent flood events on the NSW North Coast. A promising aspect of the present concept is the low implementation effort and scalability as OceanMAPS is operationally maintained and provides routine forecasts available around the entire Australian coastline.

The case study method consisted of using the existing configuration of the river forecast system (URBS) and substituting three viable sea level input into the existing dependant rating for each coastal river gauge. The three sea level inputs were: [1] the reference tide gauge harmonic prediction, [2] the reference tide prediction plus a manually inferred anomaly adjustment and [3] the alternative sea level forecast. The results indicate that the accuracy of the peak river level forecast using URBS was not sensitive to the difference between current best practice and the proposed new method; i.e. very similar peaks resulted from using either input [2] or [3] above. However, decreasing the extent to which operational forecasters are required to utilise the manually inferred adjustment is considered advantageous and thus it is suggested that the sea level forecasts from OceanMAPS be incorporated for operational flood forecasts in NSW.

Keywords: Ocean forecasting, tidal anomaly prediction, flood forecasting, flood warning, operational system. 
Taylor et al., Ocean meets River: connecting Bureau of Meteorology ocean forecasts and river height predictions for improved flood warnings

\section{INTRODUCTION}

\subsection{Scope and motivation}

The Australian Bureau of Meteorology's flood and ocean forecasting systems effectively overlap at places where rivers meet the ocean. Operational oceanography is a relatively new capability and there are unexplored opportunities for information exchange between these forecast systems. The scope of the present paper is limited to a simple case study asking: "Could the existing coastal river flood forecasting system benefit from OceanMAPS sea level anomaly forecasts as an input?" While only a few very recent events from the NSW North Coast are considered, the concept is in principle applicable to any coastal river within the flood forecasting system and is based on existing operational systems.

The Australian Bureau of Meteorology provides services well beyond meteorology that are now described as 'environmental intelligence' (Bureau of Meterology, 2010). On a day-to-day basis, the different specialised services of the Bureau can operate quite independently, and this is the case with flood and ocean forecasting functions. However, the subject matter distinction breaks down where rivers meet the ocean.

\subsection{Overview of ocean forecasting}

Operational oceanography is a relatively new capability; a key enabling technological step being the start of satellite altimetry in the early 1990's. The turbulent nature of ocean 'weather' has lead to the application of analysis and prediction methods similar to those used for numerical weather prediction (NWP). Gridded forecasts of ocean state are now generated from models based on the Navier-Stokes equations that are initialised using sequential data assimilation. The development of operational ocean forecasting is described in more detail in (Hurlburt, 2009) and (Schiller, 2011)

The Bureau currently maintains separate operational systems to analyse and forecast general ocean circulation, surface waves, sea surface temperature, tsunami and tides. Tide prediction has an important and unique place in ocean forecasting (Cartwright, 2000). The Bureau formally incorporated a tidal function in the form of the National Tidal Centre (NTC) in 2004. Sea level is however not entirely periodic and deviations from the tidal pattern are described variously as the 'tidal anomalies or residual', 'meteorological effects' or 'surge'.

The OceanMAPS Ocean Model, Analysis and Prediction System (Brassington et al., 2007) is an operational ocean forecasting system based on three components:

- Global 3D ocean model MOM4 (Griffies et al., 2008), configured with eddy-resolving resolution in the Australian region;

- Data assimilation system BODAS (Oke et al., 2008) and

- Real-time quality controlled observations together with NWP fluxes.

Importantly, OceanMAPS is non-tidal in that it intentionally excludes astronomical tidal forcings and observations. Similarly excluded is the direct effect of atmospheric pressure; the 'inverse barometer'. The Sea Level Anomaly (SLA) quantity from OceanMAPS can then be meaningfully compared to an observed tidal residual adjusted for the inverse barometer. While the primary purpose of OceanMAPS is to model the global open ocean circulation, the coastal SLA signal has been shown to have forecast skill at many tide gauge locations (Taylor et al., 2010).

OceanMAPS is currently in operational transition from v1.0c to v2.0. Amongst the various upgraded features is the introduction of a daily schedule of 7-day forecasts and 3-hourly output of SLA. Consequently only OceanMAPS v2.0 is used for the present study. Also new to OceanMAPSv2.0 is a four member time-lagged (daily) forecast ensemble (Branković et al., 1990). The lagged ensemble can offer an estimate of forecast spread, however the value of any spread estimate to flood forecasting has not been investigated in this paper.

\section{METHOD}

The concept for the present study is to keep the existing river model configuration unchanged and simply exchange alternative sea level inputs for a tangible operational case. The idea is shown schematically in Figure 1. In summary, three alterative inputs were tested:

1. Harmonic reference tide only;

2. Harmonic reference tide + static offset determined heuristically by forecaster; 
Taylor et al., Ocean meets River: connecting Bureau of Meteorology ocean forecasts and river height predictions for improved flood warnings

3. Sea level forecast.

Whereas previous studies have employed a hydrodynamic model (Baddiley, 2000) or an event-based localised storm surge model (Leahy et al., 2007) to produce an estuary or sea level input, the present concept uses the more recently available routine output of existing operational systems that are national in spatial scope. This newly acquired capability is particularly attractive with regard to operationalisation.

\subsection{Primary tool for flood warnings is river flow modelling with URBS}

Flood warnings are issued by the Bureau of Meteorology when river levels are expected to exceed the prescribed flood levels. River height forecasts are developed by the operational forecasters using hydrological modelling, the interpretation of current observations and other associated techniques. The Bureau uses the URBS event-based semi-distributed runoff routing model (Carroll, 1998). The modelling is focused on distinct flood events with rainfall loss parameters adjusted during an event to determine the amount of rainfall that is routed as runoff. These parameters are set by matching the modelled and real-time observed river height at flood gauges with pre-determined ratings; typically the same sites for which warnings are issued. The URBS model simulates volumetric streamflow using a rating curve to convert between flow rate and river height at the river gauge location. The rating curve is generally a 1-1 mapping between height and flow that takes account of river slope, channel geometry and other factors at the gauge location. Traditionally river gauge ratings are developed by means of onsite topographic surveys of river cross-section and measurements of river flow profiles. Where in-situ ratings are not available or insufficient, the method of Wright and Malone (2008) can be used to develop a synthetic rating. In essence the method involves adjustment of a synthetic rating using a calibrated hydrological model (URBS) together with observations from a downstream river gauge.

Wright and Malone's method is also employed to develop ratings at locations close to the coast where the river is tidally influenced. At such locations a 2-1 mapping, called a 'dependant rating', is determined by incorporating an additional dependency on ocean tide height. The synthetic rating is adjusted to match a 'downstream' signal from an ocean tide gauge. Typically this tidal input is taken as the harmonic prediction for a nearby tide gauge; that may in fact be some hundreds of kilometres distant.
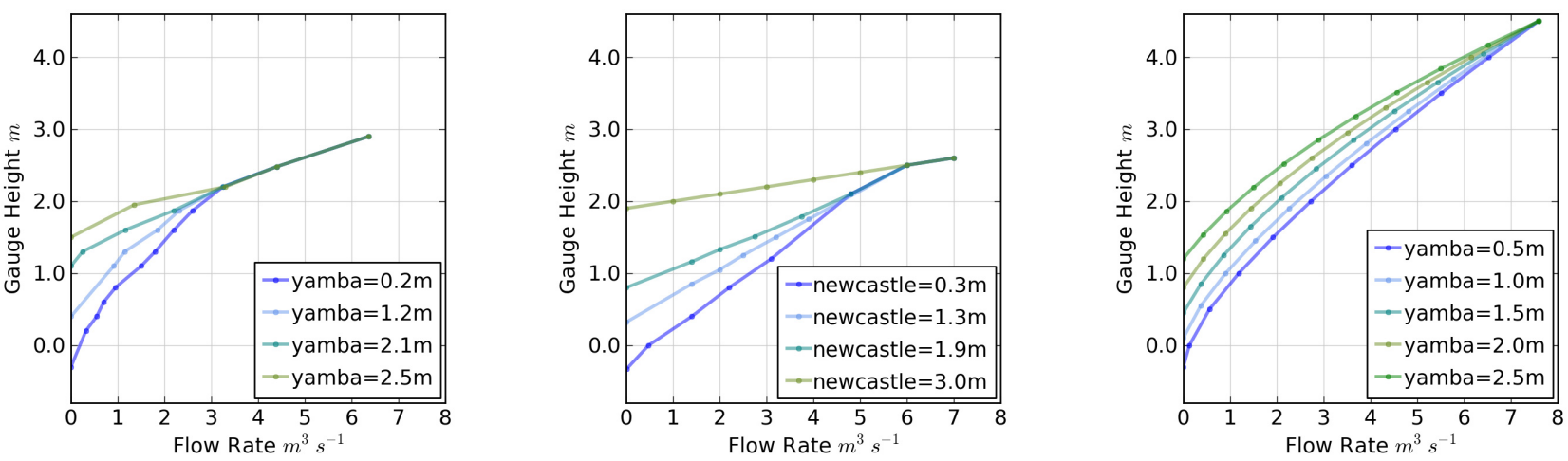

Figure 2. Ratings curves corresponding to sea levels at the reference tide gauge Locations left to right: (a) Urunga (b) Settlement Point and (c) Laurieton

A dependant rating curve is a convenient parameterisation of potentially very complex estuarine dynamics. In general, the dependency shows a diminishing impact of sea level on river height for a larger flood event with a greater flow velocity as shown in Figure 2 for three locations on the NSW coast. Due to data availability, many dependant ratings have been established using tide predictions for locations away from the 
Taylor et al., Ocean meets River: connecting Bureau of Meteorology ocean forecasts and river height predictions for improved flood warnings

river in question. The subset of locations for which official predictions are available is mostly limited by the requirement for a long record of uninterrupted high quality observations. The NTC refers to such stations as Standard Ports. Using remote predictions in effect also incorporates a type of transfer function into the dependant rating; one that maps the tidal prediction at the reference site to an ocean influence at the river gauge. For the particular locations in this study the reference tide prediction is actually the nominal Standard Port prediction manually lagged by 1 hour.

Tidal fluctuations generally account for most of the coastal ocean signal, but forecasters have heuristic tools to account for any additional anomalous ocean influence. Primarily the forecaster has the option to infer a constant tidal anomaly in the process of fitting recent river level observations to the URBS output. This tidal anomaly parameter may also be estimated via parametric relationships for the inverse barometer and local wind setup. In practice, the forecasters do not have a lot of confidence in the parametric relationships and place more credence in using a static offset ('persistence') based on the differences between observed and expected levels in developing their forecasts. It is however recognised that persisting a static offset underplays the existence of time dependant anomalies and remotely generated sea level fluctuations such as coastally trapped waves (Church and Freeland, 1986).

\subsection{Alternative sea level forecast input}

At present there is no single operational system which directly forecasts all of the leading components of observable sea level. However, the Bureau's relatively new operational suite invites a decomposition of total sea level into subsignals corresponding to three separate routine systems:

- Periodic from harmonic analysis;

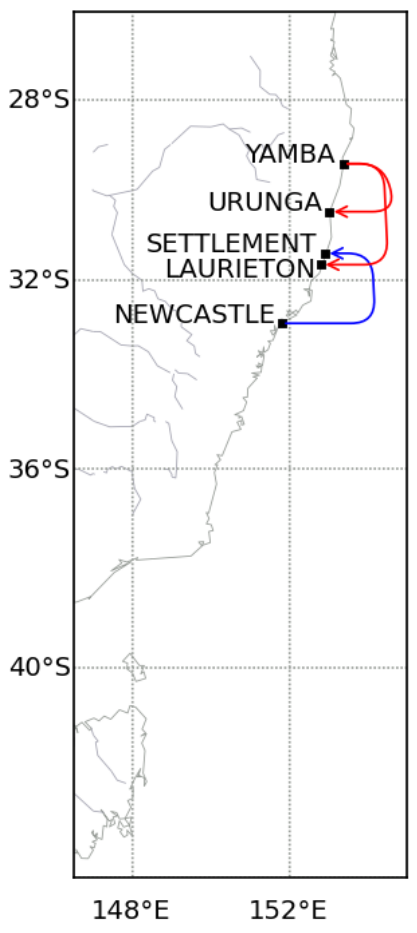

Figure 3. Station locations and reference standard ports

- Sea level anomaly from OceanMAPS and

- Local inverse barometer approximation from NWP.

While a simple linear superposition of these forecasts neglects the non-linear interactions between subsignals, it does capture many nonlinear effects within each category and has been demonstrated to be a reasonable approximation of background sea level. With regard to the linear superposition, two important nuances that arise are mentioned here for completeness without full development. Firstly there is a need to reduce each signal to a compatible datum to avoid offset bias. Secondly there is possible spectral 'double dipping' in the special cases where phenomena are represented in multiple subsignals (eg. radiational tides and seasonal cycles).

Tide predictions are in practice limited to locations of long record and high quality observations; the Standard Ports. Spatially gridded tide predictions are not likely to attain the skill of in-situ analysis for the immediate future (Ray et al., 2010) but are worthy of further investigation. The motivation of the present study is to demonstrate the simplest viable incremental change and treat URBS as a 'black box' with fixed dependant ratings. The subsequent construction of alternative sea level inputs is illustrated schematically in Figure 1. Note the spatial separation between the tidal and non-tidal forecast components.

\section{CASE STUDY SETTING}

Three coastal river gauges used for this case study are shown in Figure 3 together with the tidal Standard Ports used for the dependant rating. For the present study, the only site for which both observed and predicted tides are available is Yamba.

Figure 4 shows recent time series of observed tidal anomalies (i.e. observation minus prediction) overlaid with successive daily forecasts of non-tidal sea level from OceanMAPSv2.0 and Bureau of Meteorology operational NWP (ACCESS-R). The predicted tide at Yamba does not account for the full ocean signal with recurrent residuals of $10 \mathrm{~cm}$ to $30 \mathrm{~cm}$ evident. The fact that actual sea level is not fully accounted for by the harmonic tide is relevant for the present application to flood forecasting for river gauges at which a dependant rating has been developed. Specifically, the choice of curve for converting between flow rate and 
Taylor et al., Ocean meets River: connecting Bureau of Meteorology ocean forecasts and river height predictions for improved flood warnings

gauge height at Urunga and Laurieton (Figure 2) on a particular date could be quite inconsistent with the original development of the synthetic rating based on the Yamba tide gauge.

Overall the OceanMAPS forecasts provide a viable approximation to the time dependant non-tidal component of background coastal sea level. The lagged ensemble of non-tidal sea level forecasts at Yamba shown in Figure 4 show extremes with excellent agreement and other periods where there is significant spread to indicate significant sensitivity to the forcing conditions; this spread in principle provides valuable guidance with regard to forecast uncertainty. The underestimation of non-tidal sea level just after the flood events is noteworthy as being a possible direct influence of river outflow on the coastal ocean. OceanMAPSv2.0 does not include river boundary conditions based on real time observations and thus this anomalous forecast error following a known flood event is tentatively attributed but not investigated further at present.

Heavy rains as a result of an East Coast Low (ECL) event in early June 2011 were the primary trigger for the flood warnings, though the timing and height of coastal sea levels played a role for the lower reaches of the catchments. Harmonic tides represented the majority of sea level and the dates involved were close to a maxima in the tidal spring-neap cycle. Some significant non-tidal signal was also present, as discussed above. The weather situation over preceding days and distant sections of the coast played a part in influencing the local non-tidal sea level. Strong winds much further south drove a coastally trapped wave (CTW) that

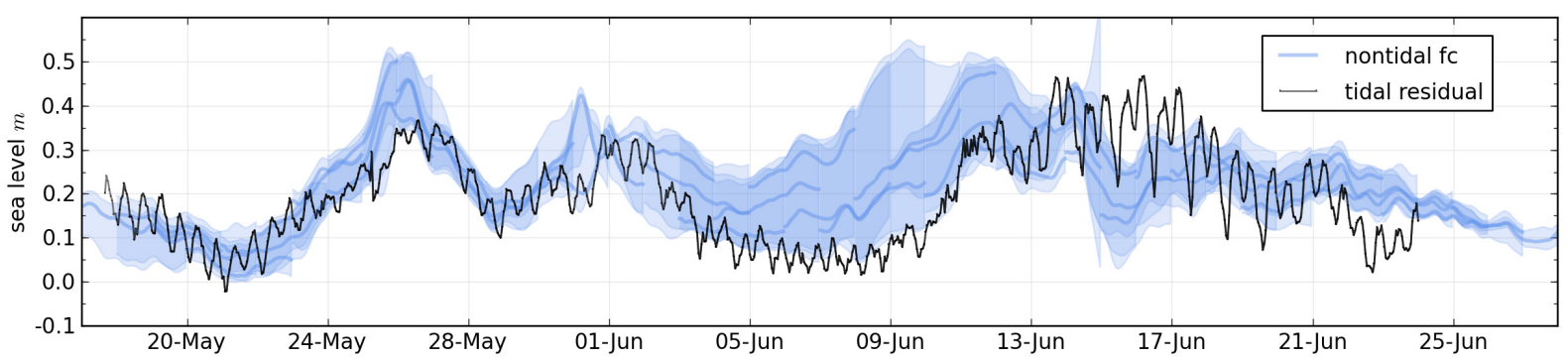

Figure 4. Yamba observed and forecast non-tidal sea level. The case study events occured around 14-June. Shading indicates approximate forecast spread based on variance across the lagged ensemble members. Note that only the most recent ensemble member and no account of spread was applied to the URBS cases.

propagated north from Victoria into the study area. The CTW signal was apparently counteracted by the interaction with the effects of coastal upwelling associated with more local winds.

\section{RESULTS}

Flood warnings issued by the Bureau require predicting peak river heights with appropriate timing. It is emphasised that the current forecasting methods can achieve remarkable accuracy and the proposed approach is not motivated by a need for radical improvement in this regard; see Discussion section below.

The results show that the peak levels at Urunga, Settlement Point and Laurieton are well modelled using the existing URBS configuration with any of the three options for the sea level input discussed here; Harmonic Tide, Harmonic Tide plus an inferred anomaly and Sea Level Forecast.

Observed and modelled river level for the event at Settlement Point are shown in Figure 5b. In the context of providing flood warnings, it is evident that the model provides a very good approximation of the main peak for each of the sea level inputs.

Similar conclusions for Urunga and Laurieton can be drawn from the results shown in Figure 5a and 5c, although at these sites an anomaly adjustment of $0.2 \mathrm{~m}$ was inferred by the forecaster to best fit the peak. Some distinction between the model outputs can be seen away from the peak, including at the initial crossing of the warning threshold on the previous day. 
Taylor et al., Ocean meets River: connecting Bureau of Meteorology ocean forecasts and river height predictions for improved flood warnings
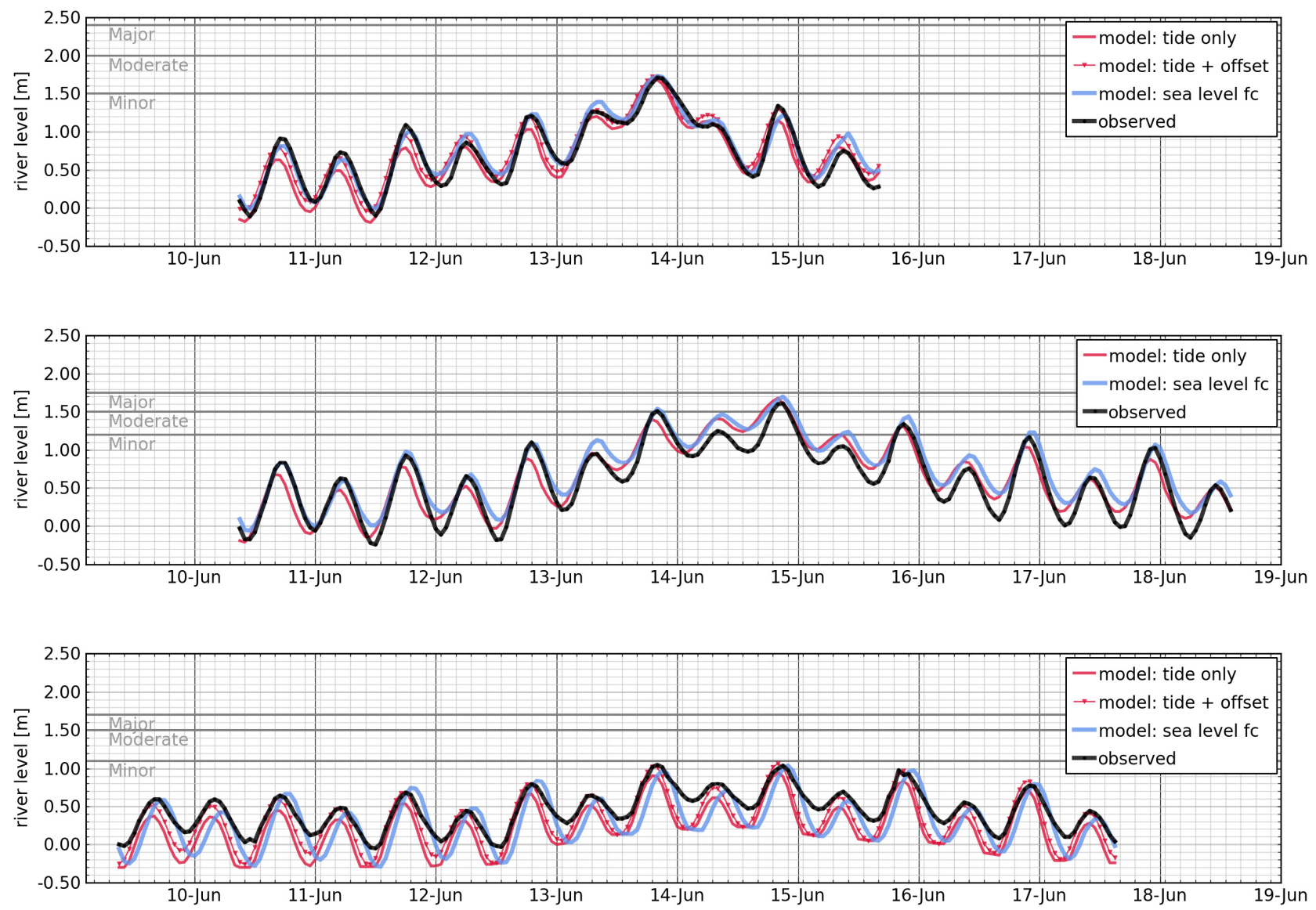

Figure 5. Modelled river height from URBS and observations.

Locations top to bottom: (a) Urunga (b) Settlement Point and (c) Laurieton

Note that forecasters determined to infer no offset for the Settlement Point case.

\section{DISCUSSION AND CONCLUSIONS}

As expected, the impact of the alternative sea level forecast on modelled river levels for the case study was certainly not exceptional. However, the marginal differences shown can actually be considered an affirmative result with regards to the potential value of the proposed concept to Operations.

It is reiterated that hydrology forecasters are primarily focussed on correctly anticipating the behaviour of flood water travelling down the rivers through the catchment. Practical use of URBS requires the forecaster to perform manual data assimilation by tuning numerous parameters in light of recent observations. The results presented above add weight to the expectation that routine sea level forecasts could reduce the amount of manual data assimilation required by the forecasters and therefore improve the timeliness and quality of flood warnings. Although not tested directly in this study, the most viable operational methodology may well be to combine the sea level forecast with the optional manual assimilation by the forecaster to account for any differences between observed and forecast levels.

It is suggested that the sea level forecasts described be made available for operational flood forecasts.

Given the very limited extent of the present study, it is further recommended that more comprehensive evaluation of the skill of coastal sea level forecasts based on OceanMAPSv2.0 are undertaken at relevant locations across Australia. Particular attention is expected to be required for the treatment of extreme nontidal phenomena given that skill will vary geographically. 
Taylor et al., Ocean meets River: connecting Bureau of Meteorology ocean forecasts and river height predictions for improved flood warnings

\section{ACKNOWLEDGMENTS}

Many thanks to NSW regional office hydrology staff for valuable input and discussion.

OceanMAPS was developed under the BLUElink> project, a partnership between the Royal Australian Navy, Bureau of Meteorology and CSIRO.

\section{REFERENCES}

Baddiley, P. (2000), Assessment of Hazards from River and Combined Storm Surge and River Flooding, in WMO Regional Technical Conference on Tropical Cyclones and Storm Surges Chiang Mai, Thailand 13-17 November 2000, pp. 1-10.

Branković, Č., T. N. Palmer, F. Molteni, S. Tibaldi, and U. Cubasch (1990), Extended-range predictions with ECMWF models: Time-lagged ensemble forecasting, Q. J. R. Meteorol. Soc., 116(494), 867-912, doi:10.1002/qj.49711649405.

Brassington, G. B., T. Pugh, C. Spillman, E. Schulz, H. Beggs, A. Schiller, and P. R. Oke (2007), BLUElink> Development of Operational Oceanography and Servicing in Australia, Journal of Research and Practice in Information Technology, 39, 151-164.

BureauofMeterology (2010), Strategic Plan 2010-2015, Providing Australians with environmental intelligence for safety, sustainability, well-being and prosperity, Australian Government.

Carroll, D. G. (1998), URBS-CM, A Catchment Management \& Flood Forecasting Rainfall Runoff Routing Model, 3rd ed.

Cartwright, D. E. (2000), Tides, A Scientific History, Cambridge University Press.

Church, J., and H. Freeland (1986), Coastal-trapped waves on the east Australian continental shelf. I: Propagation of modes, J. Phys. Oceanogr., 16, 1929-1943.

Griffies, S., M. Harrison, and R. Pacanowski (2008), A Technical Guide to MOM4, GFDL Ocean Group Technical Report, NOAA/Geophysical Fluid Dynamics Laboratory.

Hurlburt, H. E. (2009), High-Resolution Global and Basin-Scale Ocean Analyses and Forecasts, Oceanography, 22, 111-127.

Leahy, C., M. Entel, S. Sooriyakumaran, and G. Warren (2007), Integrating Hydrologic and Storm Surge Models for Improved Flood Warning, in MODSIM 2007 International Congress on Modelling and Simulation, L. Oxley and D. Kulasiri (eds.), pp. 1777-1781, Modelling and Simulation Society of Australia and New Zealand.

Oke, P. R., G. B. Brassington, and D. A. Griffin (2008), The Bluelink ocean data assimilation system (BODAS), Ocean Modelling, 21, 46-70.

Ray, R., G. Egbert, and E. SY (2010), Tide predictions in shelf and coastal waters: status and prospects, S. Vignudelli, K. A, C. P, and B. Jedited by, Coastal Altimetry, 191-216, doi:10.1007/978-3-642-127960 8.

Schiller, A. (2011), Ocean forecasting in the 21st century, in Operational Oceanography in the 21st Century, pp. 1-28, Springer Science+Business Media B. V.

Taylor, A., G. B. Brassington, and J. Nader (2010), Assessment of BLUElink OceanMAPSv1.0b against coastal tide gauges, CAWCR Technical Report, Centre for Australian Weather and Climate Research.

Wright, C., and T. Malone (2008), Hydrologic Techniques for Checking River Flow Ratings, in Water Down Under 2008, pp. 271-282. 